Doubt is being cast increasingly on the validity of oesophageal pressure measurements in sick infants. Indeed, even in the absence of lung disease extreme prematurity itself can sometimes render such measurements inaccurate. Without accurate and reproducible measurements of oesophageal pressure, dynamic compliance cannot be reliably measured in these groups of infants.

\section{Phototherapy for neonatal hyperbilirubinaemia}

Sir,

Drs Modi and Keay' conclude that phototherapy without measurement of irradiance is incomplete and inefficient. They would presumably like to see all neonatal units equipped with a radiometer. At a cost of $£ 300$ each and assuming one radiometer per 2000 births, this would cost the country approximately $£ 100000$. They have treated well, term babies who had no haemolysis but do not address the question of whether such babies need phototherapy, or indeed any therapy at all. ${ }^{2}$ Haven't the horse and the cart exchanged positions somewhere along the line? Unnecessary efficiency is inefficient efficiency and it has yet to be shown that babies with physiological jaundice benefit from being removed from their mothers and placed under a light with their eyes covered.

D P ADDY

Department of Paediatrics, Dudley Road Hospital, Birmingham $\mathrm{B} 187 \mathrm{QH}$

Drs Modi and Keay comment:

Dr Addy mistakes the point. Our study addressed itself to the question of whether the effectiveness of phototherapy, as currently used, might be improved. ${ }^{1}$ We did not, as he so rightly points out, question whether healthy babies with physiological jaundice require treatment at all.

A reasonable inference from our finding that phototherapy is used badly in well babies is that it is also used badly when its effectiveness is critical-in sick, preterm babies and in rhesus haemolytic disease.

We are also among those who believe that phototherapy is frequently used unnecessarily. While the question of treatment in well, term babies is debated, however, we feel any treatment considered necessary should be effective. We do not suggest that every neonatal unit in the country be equipped with a radiometer; we do, however, suggest that units providing intensive care are. We further suggest that manufacturers of phototherapy units provide irradiance specifications and that paediatricians appreciate that better use may be made of existing units.

\section{References \\ ' Modi N, Keay AJ. Phototherapy for neonatal hyper- bilirubinaemia: the importance of dose. Arch Dis Child 1983;58:406-9. \\ 2 Watchko JF, Oski FA. Bilirubin $20 \mathrm{mgm} / \mathrm{dL}=$ Vigintiphobia. Pediatrics 1983:71:660-3.}

\section{Fibrin stabilising factor in Schönlein-Henoch syndrome}

Sir,

We read with interest the article by Dalens et al ${ }^{1}$ which supports our own data. ${ }^{2}$ In a similar study we showed that some patients have low activity of fibrin stabilising factor in the acute phase of Schönlein-Henoch purpura. Determination of the fibrin stabilising factor in the early stage of Schönlein-Henoch purpura seems to be useful in the prognosis and management of patients, especially those with nephritis. The authors have stated in the summary that an increase in fibrin stabilising factor is associated with recovery. We believe, however, that this is not true in patients with Schönlein-Henoch purpura nephritis. Our results suggest that it is possible for the nephritis to progress after fibrin stabilising factor values return to normal and because of this, patients with a low fibrin stabilising factor value in the acute phase of disease deserve close follow up even if they show a later increase.

\section{References}

1 Dalens B, Travade P, Labbé A, Bezou MJ. Diagnostic and prognostic value of fibrin stabilising factor in Schönlein-Henoch syndrome. Arch Dis Child 1983;58:12-4.

2 Yoshioka K, Miyata H, Maki S. Significance of decreased factor XIII in Schönlein-Henoch purpura. Acta Paediatrica Japonica 1980;22:51-5.

Kazuo Yoshioka Department of Pediatrics, Kinki University School of Medicine Sayama, Minamikawachi, Osaka 589, Japan 